\title{
Translocation of Synaptically Connected Interneurons across the Dentate Gyrus of the Early Postnatal Rat Hippocampus
}

\author{
Yury M. Morozov, Albert E. Ayoub, and Pasko Rakic \\ Department of Neurobiology and Kavli Institute for Neuroscience, Yale University School of Medicine, New Haven, Connecticut 06510
}

\begin{abstract}
Most neurons in the developing mammalian brain migrate to their final destinations by translocation of the cell nucleus within their leading process and immature bipolar body that is devoid of synaptic connections. Here, we used a combination of immunohistochemistry at light- and electron-microscopic (EM) levels and time-lapse imaging in slice cultures to analyze migration of synaptically interconnected, cholecystokinin-immunopositive $[\mathrm{CCK}(+)]$ interneurons in the dentate gyrus in the rat hippocampus during early postnatal ages. We observed dynamic morphogenetic transformation of the CCK $(+)$ interneurons, from a horizontal bipolar shape situated in the molecular layer, through a transitional triangular and then vertical bipolar form that they acquire while traversing the granular layer to finally assume an adult-like pyramidal-shaped morphology on entering the hilus. Immunostaining with anti-glial fibrillary acidic protein and three-dimensional reconstructions from serial EM images indicate that, unlike granule cells, which migrate from the hilus to the granular layer, interneurons traverse this layer in the opposite direction without apparent surface-mediated guidance of the radial glial cells. Importantly, the somas, dendrites, and axons of the $\mathrm{CCK}(+)$ transitional forms maintain old and acquire new synaptic contacts while migrating across the dentate plate. The migration of synaptically interconnected neurons that may occur in response to local functional demand represents a novel mode of cell movement and form of neuroplasticity.
\end{abstract}

Key words: cholecystokinin; development; migration; innervation; electron microscopy; 3D reconstruction; live imaging

\section{Introduction}

Most of the neurons in the laminar structures of the mammalian brain acquire their final positions by radial and tangential migration (Rakic, 1990; Marin and Rubenstein, 2003). Both modes of migration involve translocation of the cell nucleus and surrounding cytoplasm within a leading process devoid of synaptic contacts (Rakic, 1971, 1972; Hatten, 1999). However, projection neurons and interneurons may use different navigation cues for achieving their final positions (Polleux et al., 2002; Ang et al., 2003; Stumm et al., 2003; Tanaka et al., 2003; Flames et al., 2004). In the hippocampus, interneurons of distinct neurochemical types display characteristic laminar and regional distribution (Freund and Buzsaki, 1996). Thus, parvalbumin-, calretinin-, somatostatin-, and cholesystokinin-immunopositive [CCK $(+)]$ cells are concentrated in the hilus along its border to the granular layer and are rare in the molecular and external strata of the granular layer (Nunzi et al., 1985; Kosaka et al., 1987; Leranth et al., 1990; Gulyas et al., 1992; Acsady et al., 1996). Despite the functional importance of interneurons (Freund and Buzsaki,

Received Jan. 20, 2006; revised March 7, 2006; accepted April 1, 2006.

This work started while Y.M.M. was supported by IBRO at the Institute of Experimental Medicine, Hungarian Academy of Sciences in Budapest and continued at Yale University, supported by the United States Public Health Service and Kavli Institute for Neuroscience (P.R.). We are grateful to Tamas F. Freund and Richard S. Nowakowski for their helpful discussions. The monoclonal antibody raised against CCK was provided by CURE/Gastroenteric Biology Center, Antibody/RIA Core, National Institutes of Health Grant DK 41301.

Correspondence should be addressed to Dr. Pasko Rakic, Department of Neurobiology, Yale University School of Medicine, P.0. Box 208001, New Haven, CT 06510-8001. E-mail: pasko.rakic@yale.edu.

DOI:10.1523/JNEUROSCI.0272-06.2006

Copyright $\odot 2006$ Society for Neuroscience $\quad$ 0270-6474/06/265017-11\$15.00/0
1996; Ben-Ari et al., 2004), little is known how neurochemically distinct subpopulations acquire their final positions.

The production peak of hippocampal interneurons in rodents precedes the generation of pyramidal and granule neurons (Lubbers et al., 1985; Soriano et al., 1986). Several groups showed that cortical and hippocampal GABAergic cells in rodents originate from the ganglionic eminences of the embryonic basal telencephalon and then migrate in a lateral-to-medial direction through the cerebral wall during the late prenatal period (Anderson et al., 1997; Wichterle et al., 1999; Nery et al., 2002; Lopez-Bendito et al., 2004; Yozu et al., 2005). Although most interneurons terminate their migration within the neocortex, some continue migration to the hippocampal region of the archicortex (Pleasure et al., 2000; Polleux et al., 2002). Morphological analysis and quantification of $\mathrm{CCK}(+)$ cell size, shape, and numbers during the early postnatal period revealed that a major portion of this interneuron subpopulation translocates from the stratum oriens to the stratum radiatum. However, a subgroup of $\mathrm{CCK}(+)$ cells relocates from the molecular layer to the hilus of the dentate gyrus, where they reach their final position by the 12 th postnatal day (Morozov and Freund, 2003). These findings are in line with previous reports that glutamate decarboxylase 67 mRNA-containing GABAergic neurons migrate from the molecular layer, across the granular layer, to its border with the hilus of the dentate gyrus (Dupuy and Houser, 1997). More recently, radial translocation of interneurons during the first postnatal week was also documented in the rodent cerebral cortex (Hevner et al., 2004), suggesting that postnatal relocation of interneurons may be a broader phenomenon.

In the present study, we investigated morphogenetic transfor- 
mation and the concomitant translaminar migration of CCK $(+)$ interneurons across the rat dentate gyrus during the early postnatal development, with emphasis on their input and output synaptic interconnections. We performed three-dimensional (3D) reconstructions from serial ultrathin sections of $\mathrm{CCK}(+)$ and CCK-immunonegative $(-)$ cell somas and nuclei in relation to $\operatorname{GFAP}(+)$ glial cells, as well as time lapse imaging of their migration in hippocampal slices.

\section{Materials and Methods}

Animals. All animal protocols were approved by the Institutional Animal Care and Use Committees and comply with the National Institutes of Health guidelines for animal care and use. Newborn postnatal day 0 (P0; $n=4), \mathrm{P} 2(n=7), \mathrm{P} 4(n=6), \mathrm{P} 8(n=5), \mathrm{P} 12(n=3)$, and $\mathrm{P} 20(n=3)$ Wistar rats were used for the immunohistochemical and correlative light/electron microscopy (LM/EM) study, whereas P5 ( $n=7$ litters) rats were used for slice culture preparations. Fixation and immunolabeling was performed according to the protocols described earlier (Morozov and Freund, 2003). Briefly, animals were deeply anesthetized with chlornembutal $(0.03 \mathrm{ml} / 10 \mathrm{~g})$ and perfused transcardially by a fixative containing $4 \%$ paraformaldehyde, $0.2 \%$ picric acid, and $0.1 \%$ glutaraldehyde in $0.1 \mathrm{M}$ phosphate buffer.

Immunohistochemistry. The brains were removed from the skull and coronal, $60-\mu \mathrm{m}$-thick sections from the blocks containing the dorsal hippocampus were cut by a Vibratome (VT1000S; Leica, Nussloch, Germany). After extensive washes, the sections were freeze-thawed over liquid nitrogen, blocked in $5 \%$ bovine albumin, and incubated in a mouse anti-CCK monoclonal (CURE Gastroenteric Biology Center, Los Angeles, CA; dilution 1:10,000), a rabbit anti-GFAP polyclonal antisera (DakoCytomation, Glostrup, Denmark; dilution 1:1000), or a mixture of both for fluorescent double immunolabeling for $48 \mathrm{~h}$ at $+4^{\circ} \mathrm{C}$. The sections for correlative $\mathrm{LM} / \mathrm{EM}$ study were immersed in respective solutions of biotinylated goat anti-mouse or goat anti-rabbit IgGs (1:300) and developed by Elite ABC kit (Vector Laboratories, Burlingame, CA) with $3,3^{\prime}$-diaminobenzidine- $4 \mathrm{HCl}(\mathrm{DAB})$ as a chromogen. For fluorescent microscopy, Alexa A-594-anti-mouse- and Alexa A-488-anti-rabbitconjugated IgGs (Invitrogen, Eugene, OR; dilution 1:300) were used as the secondary antibodies. Specificity of the method was tested by omitting the primary antibody from the staining procedure. No nonspecific staining was observed in negative control sections.

Correlative light/electron microscopy and three-dimensional reconstruction. For correlative LM/EM study, the sections were postfixed with $1 \%$ $\mathrm{OsO}_{4}$, dehydrated, and embedded in Durcupan (ACM; Fluka, Buchs, Switzerland) on microscope slides and coverslipped. Selected immunolabeled cells were traced with Neurolucida and photographed with an Axioplan 2 microscope (Zeiss, Jena, Germany). Photomontages from micrographs made with different focal planes were mounted using Adobe (San Diego, CA) Photoshop 7.0 software. For electronmicroscopy investigations, selected areas were re-embedded into Durcupan blocks and cut by a Reichert ultramicrotome into 70-nm-thick sections. Long series of sections (up to 200) were collected using Domino rack (EMS, Fort Washington, PA) (Rowley and Moran, 1975). These sections were then stained with uranil acetate and lead citrate and evaluated in a JEOL (Peabody, MA) 1010 electron microscope equipped with Multiscan 792 digital camera (Gatan, Pleasanton, CA). Serial images of arbitrarily selected cells were made with $10,000 \times$ magnification of the electron microscope. Three-dimensional reconstruction of cell bodies and measurement of volume and surface area of the reconstructed nuclei were performed using the computer program Reconstruct (Fiala and Harris, 2001), publicly available at http://synapses.bu.edu. Images of every fifth serial section were used for reconstruction of nuclei of non-CCK cells. Every third serial section was photographed for reconstruction of non-CCK cells and adjacent GFAP $(+)$ processes. Every single serial section was used for reconstruction of CCK $(+)$ cell bodies, their nuclei and input synapses.

Quantitative Analysis. To determine the percentage of CCK $(+)$ cells of different morphogenetic types in the dentate plate, five to seven Durcupan-embedded sections taken from three to four animals of each age were analyzed. The immunolabeled cells of five morphogenetic types (see below) were counted using a light microscope and a $40 \times$ dry objective. The cells were considered immunolabeled if the staining intensity of their cell bodies was distinctly higher than the background and primary dendrites could be followed from them. The cells in the stratum moleculare truncated on the surface of sections for which morphogenetic type was unidentifiable were considered indefinite and calculated separately. Truncated cells in the granular layer and in the hilus were identifiable with the cell body position. The percentage of cell types was calculated for every section and the mean and SD for every cell type at each age was also calculated. Because tissue shrinkage obviously cannot change the cell morphogenetic type, no shrinkage correction was required. Statistical significance was determined using one-way ANOVA followed by Tukey's test for every time point. A value of $p<0.05$ was considered significant.

Organotypic slice cultures. Hippocampal slice explants were prepared from $\mathrm{P} 5$ rat pups taken from 7 litters as described previously (Ayoub et al., 2005). Briefly, animals were killed and the brains were removed quickly and placed in cold oxygenated artificial CSF [containing the following (in mM): $126.0 \mathrm{NaCl}, 3.0 \mathrm{KCl}, 1.3 \mathrm{MgSO}_{4}, 2.5 \mathrm{CaCl}_{2}, 1.2$ $\mathrm{NaH}_{2} \mathrm{PO}_{4}, 26 \mathrm{NaHCO}_{3}, 20$ dextrose]. The brain was supported with $3 \%$ agar and sliced at $250 \mu \mathrm{m}$ thickness on a vibroslicer (WPI, Sarasota, FL). Slices were then transferred to collagen-coated tissue culture inserts placed over $1 \mathrm{ml}$ of culture media (Neurobasal media, 5\% B27 and 1\% N2 supplements, $1 \%$ Glutamax, $10 \%$ HEPES, and $0.5 \%$ Pen/Strep) in sixwell plates and maintained at $37^{\circ} \mathrm{C}$ at $5 \% \mathrm{CO}_{2}$ atmosphere. Slices were stained with CellTracker green $\left(12.5 \times 10^{-3} \mu \mathrm{g} / \mu \mathrm{l}\right.$ in culture media; Invitrogen) for $30 \mathrm{~min}$, destained for $30 \mathrm{~min}$, then left to recover for $4 \mathrm{~h}$ before starting imaging. The remaining slices were left in the incubator until they were evaluated, but for no more than $24 \mathrm{~h}$.

Confocal imaging. Double-immunolabeled specimens were analyzed with a laser-scanning confocal microscope (Axiovert 100M; Zeiss). Merging of optical sections (five sections with a distance of $2 \mu \mathrm{m}$ in between) were used for preparing micrographs.

Multiphoton live imaging. Time-lapse experiments were performed with an $8 \mathrm{~W}$ pumped Coherent Mira 900F laser (Coherent, Santa Clara, CA) mode-locked at $800 \mathrm{~nm}$ coupled to an Axiovert 100M (Zeiss) fitted with a motorized stage. Organotypic slices $(n=22)$ were transferred to a RC25 recording chamber (Warner Instruments, Hamden, CT) maintained at $36^{\circ} \mathrm{C}$ and perfused with fresh culture media. Time series and Z-stacks ( 20 optical sections by $2 \mu \mathrm{m}$ in between within the tissue) were collected from multiple positions every 10 or $15 \mathrm{~min}$ for $10-12 \mathrm{~h}$ per slice using the Multitime 3.2 (Zeiss) module through an oil-immersed 25× objective, then exported as AVI files and edited with Adobe Premier Pro. The observation focused on the suprapyramidal blade of the dentate gyrus. Migrating cells were identified by the translocation of their somata relative to adjacent cells. Minor cell fluctuations, of soma width or less, as well as parallel and simultaneous movement of several adjacent cells because of tissue shrinkage or other factors inherent to this imaging technique were ignored. A cell was considered to move vertically if it moved toward the stratum granulosum with a direct angle $\pm 15^{\circ}$. Distances of movement were measured in the collapsed Z-stacks using the AxioVision (Zeiss) computer program. The center of the cell body was considered as the position of the cell. The calculation of the rate of migration was limited to the time frame of observed movement or imaging session, whatever was shorter. The speed of every identified migrating cell was calculated and then the average \pm SD was calculated.

\section{Results}

\section{Morphogenetic types of CCK $(+)$ interneurons in the dentate gyrus}

We divided CCK $(+)$ cells situated in the developing dentate gyrus into four morphogenetic types according to their shape and position (Fig. 1A-D). Type A cells located within the molecular layer are characterized by pronounced horizontally oriented dendritic arborization and thin collaterals that enter the granular layer (Fig. 1A). Cells of the type B show the triangular shape of the cell somas and usually exhibit single, thick proximal dendrites that enter the granular layer and several horizontal dendrites that 


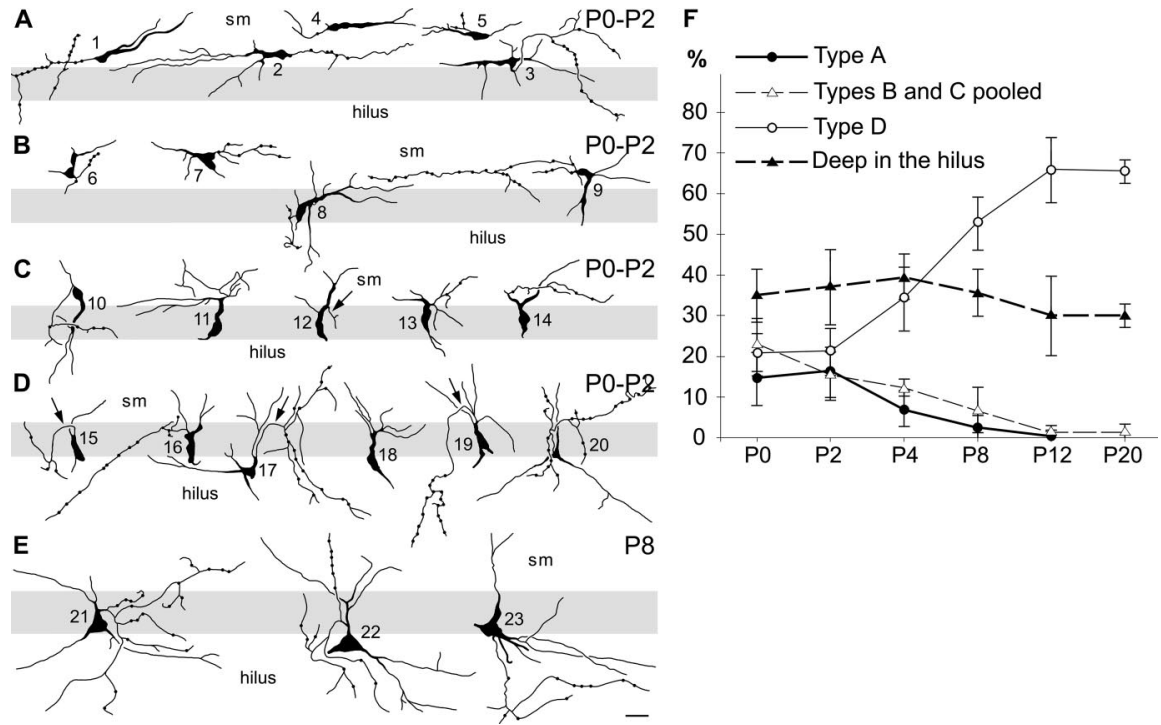

Figure 1. Neurolucida drawings of arbitrarily selected CCK $(+)$ cells from the dentate plate of postnatal rat hippocampus. $A-D$, Morphogenetic types of cells existing during first postnatal days: horizontal bipolar, vertical tripolar, vertical bipolar, and pyramidal-shaped cells, respectively. $\boldsymbol{E}$, Pyramidal-shaped $\mathrm{CCK}(+)$ cells; adult-like pattern of basket interneurons in the dentate gyrus which is mainly achieved by the eighth postnatal day. The collections of cells preserve their natural shape, size, and orientation relative to the stratum granulosum (gray strips). The cells numbered 1-3,6, 10, 15, and 16 were collected from newborn rats; the cells numbered 4-5,7-9, 11-14, and 17-20 were from 2-d-old rats. The cells numbered 1 and 9 are depicted with correlative LM and EM in Figures $3 A$ and 4 , and $3 B$ and 5 , respectively. Arrows indicate characteristic loops of axon initial segments (supplemental Fig. 1, available at www.jneurosci.org as supplemental material; see Discussion). $\boldsymbol{F}$, Dynamics of the postnatal changes in the percentage of $\mathrm{CCK}(+)$ cells of different morphogenetic types in the dentate gyrus. Note the decrease in the frequency of types $A$ and pooled B and C cells, which is paralleled by an increase in the percentage of the type $D$ cells. The percentage of the cells in the hilus remains constant, suggesting laminar translocation and morphogenetic transformation of types $A, B$, and C cells in profit of type D ones. Data represent the mean \pm SD. sm, Stratum moleculare. Scale bar: (in E) $\boldsymbol{A}-\boldsymbol{E}, 20 \mu \mathrm{m}$

remain within the molecular layer (Fig. $1 B$ ). Cells of the type $\mathrm{C}$ have bipolar-shaped cell bodies with proximal dendrites oriented vertically within the molecular and granular layers and trailing dendrites that remain in the molecular layer (Fig. 1C). Type D cells display pyramidal-shaped somas around the border of the granular layer and the hilus, with a single apical dendrite traversing the granular layer and several basal dendrites in the hilus (Fig. $1 D)$. These cells have a mature shape, although their size is distinctly smaller than in adults (compare with Fig. $1 E$ which represents adult $\mathrm{CCK}(+)$ cells predominating from P8 onwards). $\mathrm{CCK}(+)$ interneurons can also be found deep in the hilus during the entire period of postnatal development as well as in adult animals (Nunzi et al., 1985; Leranth and Frotscher, 1986; Morozov and Freund, 2003). Such cells have quasi-random dendritic orientation and probably do not translocate. This cell type is not illustrated here.

The frequency of these morphogenetic types changes systematically during the course of postnatal development, suggesting that they represent transitional morphogenetic forms. In the newborn and 2-d-old animals, the proportions of all cell types are almost equal. However, after the fourth postnatal day, the ratio of type A, B, and $\mathrm{C}$ cells starts to decrease significantly, whereas the percent of type D increases. In contrast, the percentage of $\mathrm{CCK}(+)$ cells situated deep in the hilus remains constant during the entire analyzed period. These systematic gradual changes indicate that type A, B, and C cells do not disappear, but rather move and transform into type D cells. Otherwise, the proportion of pyramidal-shaped and hilar cells in both diagrams would grow in parallel. Horizontal (type A) cells are virtually absent by the eighth postnatal day, whereas the vertical cells (pooled type B and C) comprise only $\sim 10 \%$ of all $\mathrm{CCK}(+)$ cells at this time. Type B and C cells disappear by $\mathrm{P} 12$ (Table 1, Fig. $1 F$ ). Thus, the vertical cell is a transient form between the horizontal and pyramidal-shaped ones. After P8, the characteristic pyramidal shape of the $\mathrm{CCK}(+)$ cells with one apical and several basal dendrites became a predominant form. The somas of most cells, situated in the granular layer close in proximity of the hilus, became larger (up to $20 \mu \mathrm{m}$ in diameter) and more round (Fig. $1 E$ ). Thus, the adult-like pattern of $\mathrm{CCK}(+)$ cells is basically achieved by the eighth postnatal day, although short relocation of some cells can still be in progress. Finally, in the 12 - and 20 -d-old animals, CCK $(+)$ cells are very rare in the molecular and external rows of the granular cell layers (Table 1, Fig. $1 F$ ).

To confirm that interneurons migrate across the granular layer, we used time-lapse multiphoton imaging of organotypic slices of the dentate gyrus (Fig. 2, supplemental animation, available at www.jneurosci.org as supplemental material). We tracked the migration of 137 cells in 22 slices across the region of the dentate gyrus. Among 62 cells that were migrating through the molecular layer, 49 cells (79\%) eventually moved vertically to-

Table 1. Percentage of $\mathrm{CCK}(+)$ cells of different morphogenetic types in the rat hippocampal dentate gyrus of different postnatal ages

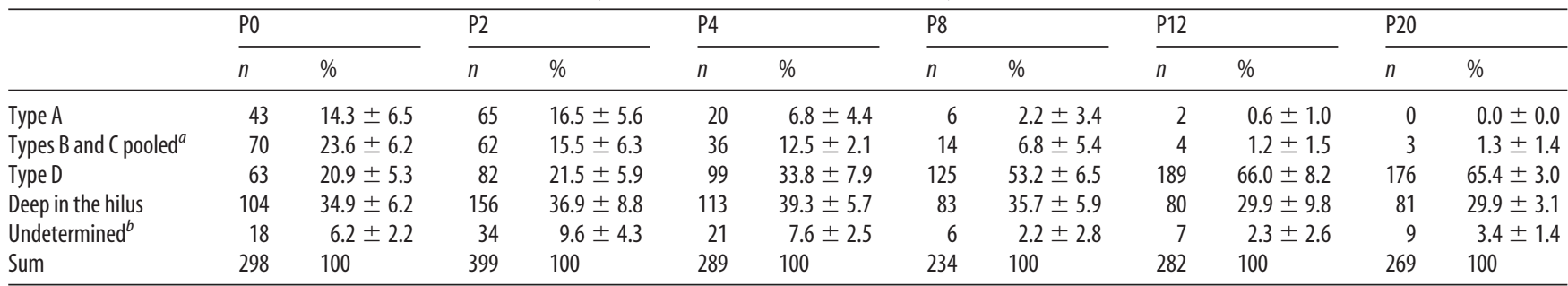

Measurements of cells "deep in the hilus" were significantly different $(p<0.05)$ from all other measurements at all time points with exception of "type D" at P4. Measurements of cells type D were significantly different $(p<0.05)$ from all other measurements at P4-P20 with exception of cells deep in the hilus at P4. All other differences were statistically not significant $(p>0.05)$. $n$, Total number of cells in analyzed sections; \%, mean calculated after analysis of four to seven sections taken from three to four animals of each age \pm SD.

${ }^{a}$ These types were pooled because they often had intermediate forms difficult to separate.

${ }^{b}$ The $\mathrm{CCK}(+)$ cell bodies in the stratum moleculare with dendrites truncated on the surface of the sections (presumed probably belong to types $\mathrm{A}-\mathrm{C}$ ). 

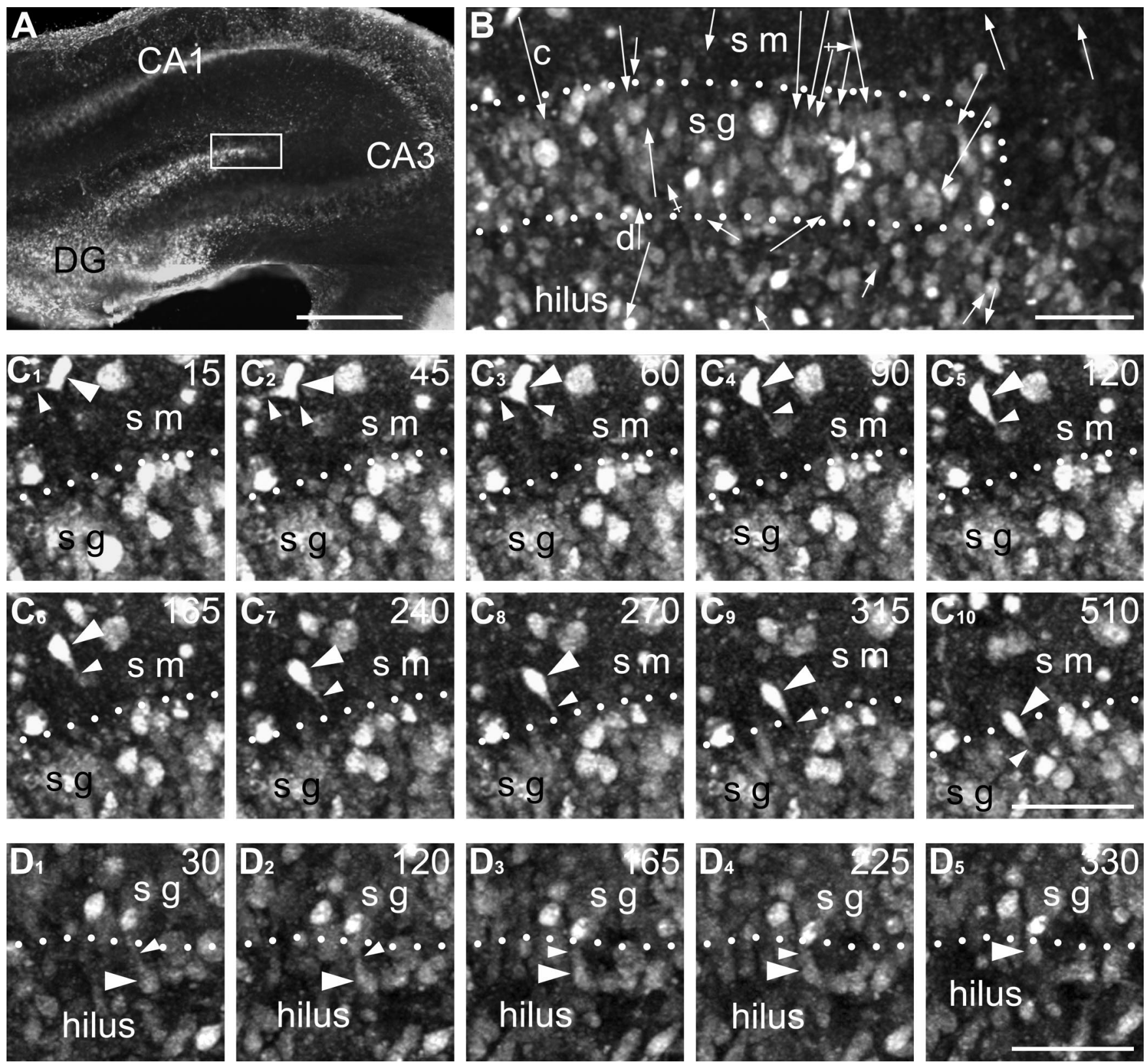

Figure 2. Time-lapse two-photon live imaging of cells around the suprapyramidal blade of the dentate gyrus from a P5 rat. $A$, Low-power image of a hippocampal section stained with CellTracker green. The framed area was evaluated with time-lapse microscopy and is depicted at higher magnification in $\boldsymbol{B}$. $\boldsymbol{B}$, High-power image of a fragment of the dentate gyrus at the beginning of the time-lapse imaging. See the animation of this experiment, available at www.jneurosci.org as supplemental material. Every arrow indicates reposition of one cell observed with time-lapse imaging. The length and direction of arrows correspond to the distance and direction of the cell migration. The length of the arrows does not characterize the speed of the cells. Arrows with a cross line indicate migrating cells, which look smaller in size and reveal no detectable leading process. Notice that arrows in the stratum moleculare (sm) tended to be oriented down in accordance with our anti-CCK immunolabeling. Arrows indicated as "c" and "d" mark translocation of the cells depicted in serial images in $\mathbf{C}$ and $\mathbf{D}$, respectively. C, D, Serial time-lapse images of arbitrarily selected cells translocating in the stratum moleculare $(\boldsymbol{C})$ and the hilus $(\boldsymbol{D})$. The positions of the cells of interest are marked with the arrowheads. The processes they emit are indicated with small arrowheads. The borders of the stratum granulosum $(\mathrm{sg}$ ) are indicated with doted lines. The number in the upper right corner of every photo indicates the time point in minutes after the beginning of live imaging. Scale bars: $\boldsymbol{A}, 500 \mu \mathrm{m} ; \boldsymbol{B}-\boldsymbol{D}, 50 \mu \mathrm{m}$.

ward the granular layer (Fig. 2B). Representative cells had well defined leading and trailing processes and had changed their orientation from horizontal to vertical migration during the observation period (Fig. 2C). These cells demonstrated morphogenetic transformation and laminar translocation similar to CCK $(+)$ interneurons observed in our LM reconstructions. Compare the cell in Figure $2 C_{1}$ with horizontal (type A) CCK $(+)$ cells in Figure 1. Compare also the same cell later (Fig. $2 C_{2,3}$ ) with the triangular (type B) cells. Finally, compare this cell (Fig. $2 C_{4-10}$ ) with the vertical (type $\mathrm{C}$ ) cells. We conclude that at least some of the migrating cells observed in the molecular layer represent migrating interneurons. In the granular layer, we identified 20 movable cells. The number of cells crossing the granular layer might be an underestimate because, as a result of high cell density, the stained cells often mask each other and, thus, we did not quantify the direction of movement. In contrast, in the hilus, among $55 \mathrm{mi}-$ grating cells, 45 cells ( $82 \%$ ) clearly moved in the opposite direction, toward the granular layer, as illustrated in Figure $2 D$. These cells probably represent new granule cells generated during this period (Altman and Das, 1965; Bayer, 1980; Altman and Bayer, 

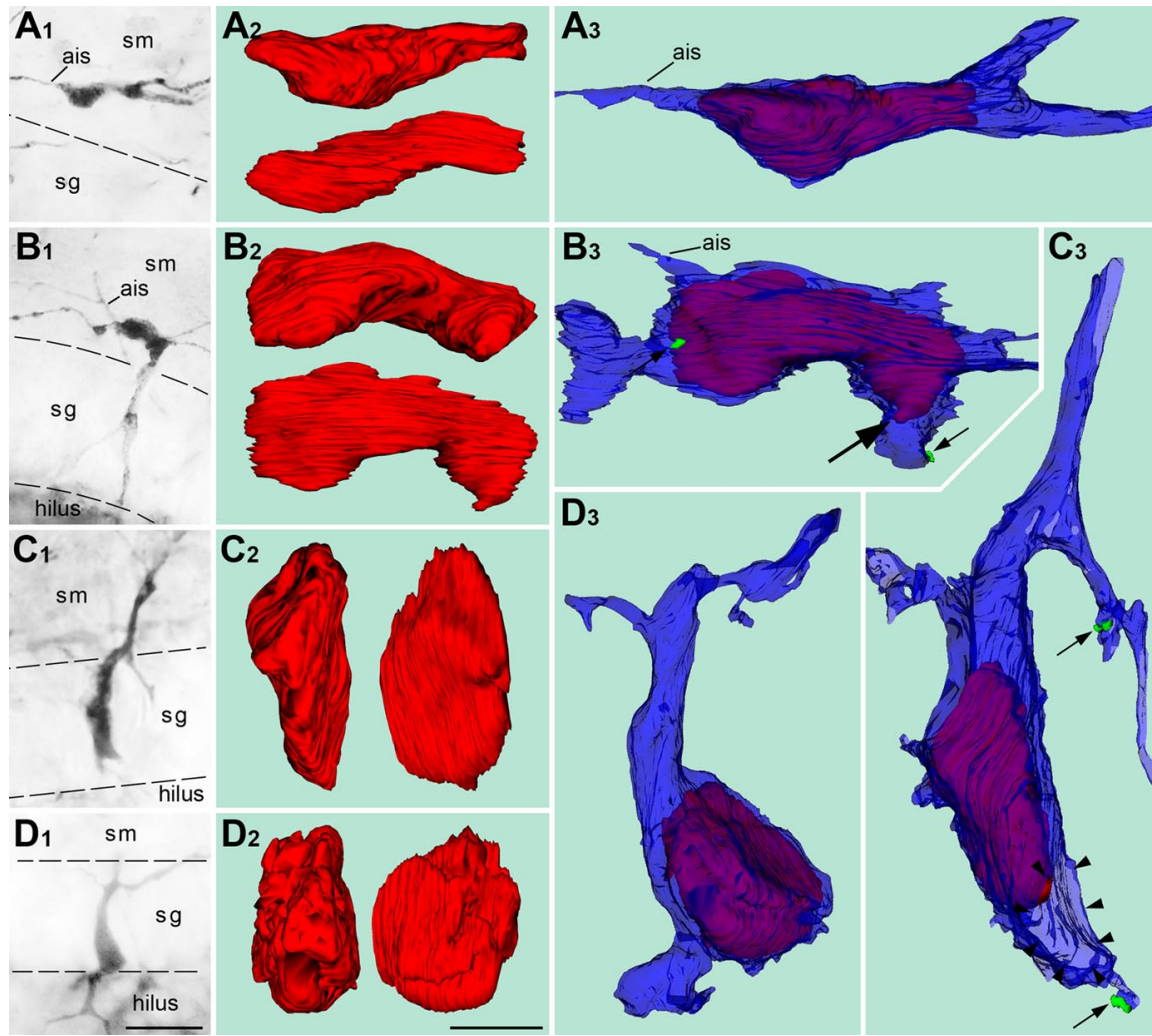

Figure 3. Correlative LM/EM analysis of CCK( + ) cells of distinct morphogenetic types. The left column of pictures demonstrates the position of cells relative to the granule cell layer. The middle column represents 3D reconstructed nuclei (red) of every cell in two reciprocal perpendicular projections. The right column illustrates positions of the nuclei inside the cell bodies (blue) depicted in semitransparent manner. $\boldsymbol{A}$, Horizontal cell (Fig. 1, cell 1) has the nucleus elongated in horizontal plane as well. $\boldsymbol{B}$, Intermediate form between horizontal and vertical bipolar cells (Fig. 1, cell 9). The main part of the nucleus is positioned in the cell body in the stratum moleculare. Notice that a tip of the nucleus (big arrow) invaded the proximal fragment of the vertical dendrite, which suggests nuclear translocation. See high-power EM images of synapses innervating this cell in Fig. 5. C, The cell traversing the granule cell layer has the nucleus elongated vertically. A side profile of the leading process is indicated with arrowheads. $\boldsymbol{D}$, Pyramidal-shaped cell demonstrates rounded-up nucleus. The borders of the stratum granulosum are indicated with dashed lines. Synaptic boutons innervating the reconstructed cells are drawn in green and indicated with small arrows. Ages: $A, D, P 0 ; B, C, P 2$. Scale bars: (in $D_{1}$ ) for all LM micrographs, $20 \mu \mathrm{m}$; (in $\boldsymbol{D}_{2}$ ) for 3D reconstructions, $5 \mu \mathrm{m}$. ais, Axon initial segment; sg, stratum granulosum; sm, stratum moleculare.

1990). We also observed smaller cells that had no detectable leading or trailing processes, and moved obliquely or along capillaries. We concluded that they are probably microglia.

We observed both fast and slowly moving cells in all layers of the dentate gyrus but their measurements were pooled for the purposes of statistical analysis. The average speed of cell migration was $10.6 \pm 6.6 \mu \mathrm{m} / \mathrm{hr}$, whereas the fastest and the slowest moving cells had speeds of 41.4 and $2.4 \mu \mathrm{m} / \mathrm{hr}$, respectively. Our data on the speed of migration are comparable with findings obtained in the slices of the mouse cerebral cortex (Nadarajah et al., 2001; Polleux et al., 2002; Ang et al., 2003; Yozu et al., 2005). However, the speed is probably an underestimation, because the interneurons in the embryonic cerebral cortex in utero move much faster than in whole brain explants (Ang et al., 2003).

\section{D reconstruction of developing $\mathrm{CCK}(+)$ interneurons}

To investigate the properties of migrating neurons, we performed EM analysis and 3D reconstruction of the cell somas, their processes and nuclei from serial ultrathin sections. The EM reconstruction has confirmed LM immunochemical findings (Fig. 3) and, in addition, helped to determine the nature of the cell processes and their synaptic relations.

The nuclei of reconstructed type A cells had a pronounced

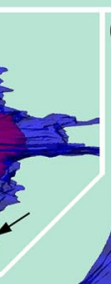

$\mathrm{C}_{3}$

horizontal orientation (Fig. $3 A$ ), which reflects their tangential migration within the molecular layer. The nuclei in type B cells (Fig. 1, cell 9), which have their soma in the molecular layer and a thick vertical dendrite in the granular layer, fit well in the cell body with a protrusion often invading the vertical dendrite (Fig. 3B). Apparently, these cells are in a phase of nuclear translocation to the granular layer. The nucleus of a vertical cell (type C, illustrated in Fig. 3C) is located entirely within the elongated cell body. We calculated the parameters of the shape of reconstructed cell nuclei as a fraction in which the numerator was proportional to the maximal length of the nucleus and the denominator was the mean of width and height in their maximal sections. The proportions of four elongated nuclei (from type A, B, and C cells) were between 4:1 and 2.5:1 (Table $2)$. Three reconstructed type D cells demonstrated rounded-up nuclei (proportions did not exceed 1.5:1) (Table 2). They displayed several invaginations of the nuclear membrane, characteristic of mature interneurons. The nuclei of type $\mathrm{D}$ cells do not enter proximal dendrites (Fig. 3D), consistent with the hypothesis that these cells have completed their nuclear and somal translocation.

Five of the seven reconstructed $\mathrm{CCK}(+)$ cells, regardless of their morphogenetic type, had nuclei of similar size $\left(\sim 170 \mu \mathrm{m}^{2}\right.$ in surface area and $\sim 190$ $\mu \mathrm{m}^{3}$ in volume), although one cell (Fig. 1, cell 1$)$ was distinctly smaller $\left(130 \mu \mathrm{m}^{2}\right.$ and $110 \mu \mathrm{m}^{3}$ ), and some type D cells are much larger (up to $260 \mu \mathrm{m}^{3}$ ). On average, the nuclei of $\mathrm{CCK}(+)$ cells at early postnatal days are distinctly bigger than $\mathrm{CCK}(-)$ interneurons and migrating granule neurons, but they are smaller than the nuclei of the mature granule cells (Table 2).

\section{Synaptic connections of CCK $(+)$ interneurons}

A large proportion of the $\mathrm{CCK}(+)$ reconstructed cells in the dentate plate have axons with few branches and distinct synaptic varicosities distributed within the hilus, as well as the molecular and granular layers already in the newborn and 2-d-old animals. Correlative LM/EM analysis of cells 1 (Fig. 4) and 9 (Fig. 5), as well as 2, 6, 16, and 19 (data not shown), confirmed that all morphological types of cells have nonmyelinated axons that formed symmetric synapses characteristic of GABAergic interneurons (Figs. 4C, 5C) (Morozov and Freund, 2003).

Cell bodies and proximal dendrites of cells 1 (Fig. 4D), 2, 6, and 16 (data not shown) had several immature synaptic contacts (puncta adherentia) with the boutons containing few synaptic vesicles. The dendrite of cell 1 also had contact with the cell body of a neuron in the molecular layer that displays ultrastructural elements of the dendrosomatic junctional complex of the puncta adherentia type (Fig. $4 E$ ).

Despite an extensive search, we did not find innervated $\mathrm{CCK}(+)$ dendrites in the dentate gyrus of newborn rats (P0). In 
Table 2. Morphogenetic characteristics of nuclei of interneurons and granule cells in the rat hippocampal dentate gyrus

\begin{tabular}{|c|c|c|c|c|c|c|}
\hline Type of the cell, postnatal age (illustrations) & Maximal length $(\mu \mathrm{m})$ & Width $^{a}(\mu \mathrm{m})$ & Height $^{a}(\mu \mathrm{m})$ & Proportions L:[(W + H):2] & Area of the surface $\left(\mu \mathrm{m}^{2}\right)$ & Volume $\left(\mu \mathrm{m}^{3}\right)$ \\
\hline \multicolumn{7}{|l|}{$\mathrm{CCK}(+)$ interneurons } \\
\hline Type A, P0 (Figs. 1, cell1, 3A, 4A) & 15.0 & 4.0 & 3.5 & $4.0: 1$ & 131 & 107 \\
\hline Type A, P2 (not illustrated) & 13.0 & 5.5 & 4.5 & $2.6: 1$ & 196 & 192 \\
\hline Type B, P2 (Figs. 1, cell 9, 3B, 5B) & 17.5 & 6.0 & 4.0 & $3.5: 1$ & 176 & 184 \\
\hline Type C, P2 (Figs. 1, cell 12,30) & 14.0 & 6.0 & 5.0 & $2.5: 1$ & 163 & 184 \\
\hline Type D, PO (Fig. 3D) & 9.5 & 7.5 & 5.5 & $1.5: 1$ & 197 & 187 \\
\hline Type D, P2 (not illustrated) & 10.5 & 8.5 & 6.0 & $1.5: 1$ & 175 & 186 \\
\hline Type D, P4 (cover page of this issue) & 10.5 & 9.5 & 9.0 & 1.1:1 & 181 & 260 \\
\hline \multicolumn{7}{|l|}{ Non-CCK interneurons } \\
\hline Type A, P4 (Fig. 7D) & 12.5 & 4.0 & 3.5 & 3.3:1 & 88 & 52 \\
\hline Type B, P4 (Fig. 7E) & 8.5 & 5.5 & 3.0 & $2.0: 1$ & 84 & 54 \\
\hline Type C, P4 (Fig. 7F) & 9.0 & 4.5 & 3.0 & $2.4: 1$ & 90 & 75 \\
\hline Type $C^{b}$, P2 (Fig. 6) & 13.5 & 7.0 & 4.0 & $2.5: 1$ & 199 & 173 \\
\hline Type D, P4 (Fig. 7G) & 10.5 & 9.0 & 4.5 & $1.6: 1$ & 169 & 100 \\
\hline \multicolumn{7}{|l|}{ Granule neurons } \\
\hline Bipolar cell, P4 (Fig. 7H) & 9.5 & 5.0 & 3.0 & 2.4:1 & 80 & 67 \\
\hline Bipolar cell, P4 (Fig. 7/) & 9.0 & 4.5 & 3.5 & 2.3:1 & 120 & 78 \\
\hline Mature cell, P2 (Fig. 6C1) & 10.0 & 8.5 & 7.0 & 1.3:1 & 158 & 299 \\
\hline Mature cell, P2 (Fig. 6(2) & 9.5 & 8.5 & 7.0 & $1.2: 1$ & 171 & 272 \\
\hline Mature cell, P2 (Fig. 6(3) & 10.5 & 10.0 & 6.0 & $1.3: 1$ & 153 & 280 \\
\hline
\end{tabular}

L, Length; W, width; $H$, height.

${ }^{a}$ Two reciprocal perpendicular diameters in their maximal section.

${ }^{b} \mathrm{CCK}(-)$ negative cell. Other non-CCK interneurons were taken from sections not immunolabeled against CCK.

contrast, all reconstructed cells after $\mathrm{P} 2$ (e.g., cells 7, 9, 12, 18, and 19) received multiple symmetric and asymmetric synapses on their bodies and dendrites. Thus, a fragment of cell 9 (Fig. 5) displays up to eight mature input synapses on the soma, vertical dendrite in the granular layer, and the horizontal dendrite in the molecular layer. Asymmetric synapses " $\mathrm{d}$ " and " $\mathrm{e}$ " display pronounced postsynaptic density. The presence of round synaptic vesicles suggests that these synapses are probably glutamatergic (Fig. 5D,E). Symmetric synapses " $\mathrm{f}$ " and "g" demonstrate thin postsynaptic density and small pleomorphic vesicles characteristic of GABAergic synaptic boutons (Fig. 5F, G). The form of invasion of the nucleus (see above) indicates that the vertical dendrites of type $B$ cells serve as a leading process for the translocation of the cell nucleus.

\section{CCK $(-)$ interneurons}

At P0-P4, low-power EM photos made on randomly taken sections across the dentate gyrus reveal numerous $\mathrm{CCK}(-)$ as well as $\operatorname{CCK}(+)$ neurons. Most of the $\mathrm{CCK}(-)$ cells were oriented tangentially in the molecular layer and radially in the granular layer (Fig. 6). The shape of the cell indicates that they are also likely engaged in migration. The finding that by P8 such cells became very rare and that they virtually disappear at P12 and P20 (data not shown) supports the conclusion that $\mathrm{CCK}(-)$ cells also pass through a transient migratory form. The vast majority of elongated cells display more electron-dense cytoplasm and darker chromatin com-

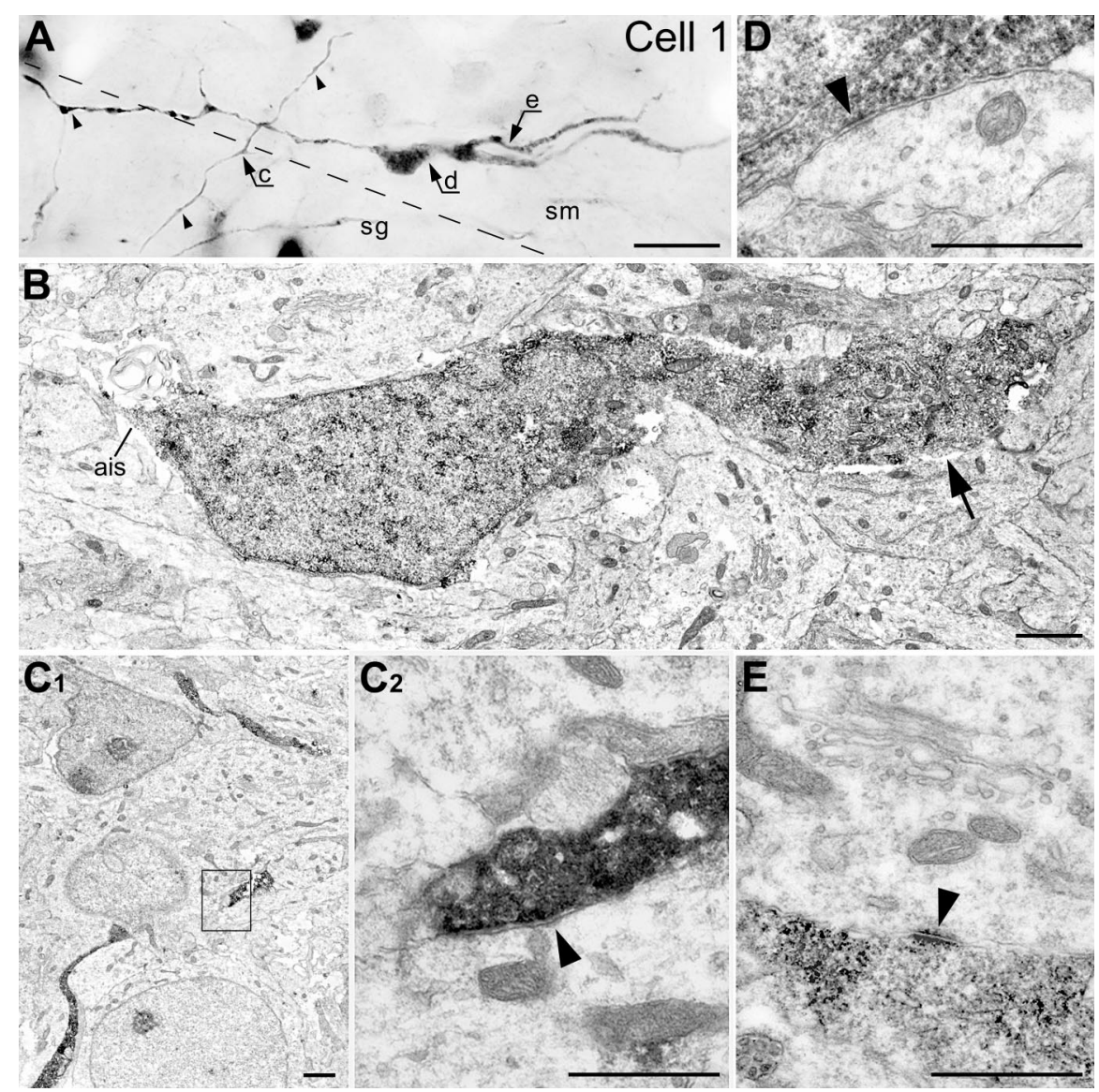

Figure 4. Correlative LM/EM analysis of the cell 1 (PO). $\boldsymbol{A}$, Photomontage from LM micrographs made with different focal planes. Notice the long heavy varicose axon (small arrowheads) spreading mostly through the stratum moleculare (sm). The border between the strata granulosum ( $\mathrm{sg}$ ) and moleculare is indicated with dashed line. Arrows $\mathrm{C}-\mathrm{e}$ indicate positions of the cell segments shown at the EM level in $\boldsymbol{C}-\boldsymbol{E}$ respectively. $\boldsymbol{B}$, Low-power electron micrograph of the cell body with a fragment of the dendrite (big arrow) and the axon initial segment (ais). $\boldsymbol{C}_{1}$, Low-power micrograph of the $\mathrm{CCK}(+)$ axon near the border of the strata granulosum and moleculare. $\boldsymbol{C}_{2}$, High-power micrograph of the area framed in $\boldsymbol{C}_{\mathbf{1}}$ depicting a symmetric presumed GABAergic synapse (arrowhead) innervating a dendritic shaft. $\boldsymbol{D}$, Electron micrograph of a puncta adherentia: an immature synapse (arrowhead) innervating the CCK(+) cell body. $\boldsymbol{E}$, Dendrosomatic junctional complex of the puncta adherentia type (arrowhead) between the $C\left(K(+)\right.$ dendrite and cell body of a neuron. Scale bars: $\boldsymbol{A}, 20 \mu \mathrm{m} ; \boldsymbol{B}, \boldsymbol{C}_{1}, 1 \mu \mathrm{m} ; \boldsymbol{C}_{2}-\boldsymbol{E}, 0.5 \mu \mathrm{m}$. 


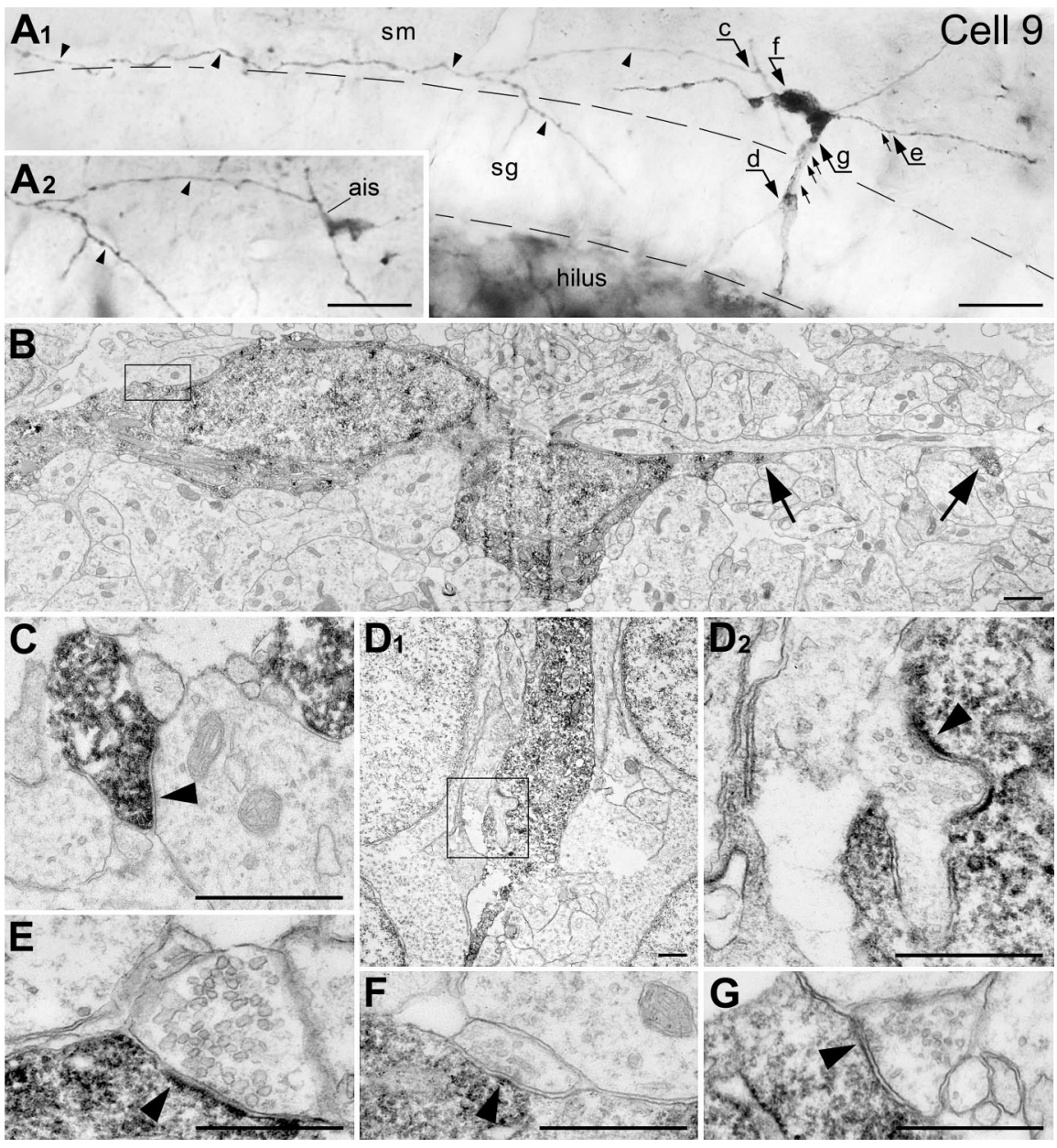

Figure 5. Correlative LM/EM analysis of cell 9 (P2). $\boldsymbol{A}$, Photomontage from LM micrographs made with different focal planes. Notice the long heavy varicose axon (small arrowheads) spreading mostly through the stratum moleculare (sm). Inset $\boldsymbol{A}_{2} \operatorname{depicts}$ the fragment of the cell with the axon initial segment (ais) after the dendrites and a big part of the cell body were cut away with ultrathin sectioning. Arrows $\mathbf{C}-\mathbf{g}$ indicate positions of synapses shown at the EM level in $\mathbf{C} \mathbf{G}$, respectively. Positions of other detected but not shown synapses are indicated with small arrows. Thick, profoundly innervated dendrite traversing the stratum granulosum $(\mathrm{sg}$ ) with a direct angle apparently serves as a leading process (see position of the nucleus inside the cell body in Fig. $3 B$ ). The borders of the granular layer are indicated with dashed lines. $\boldsymbol{B}$, Low-power electron micrograph of the cell body with fragments of horizontal (trailing) dendrite (big arrows). The framed area is depicted in $\boldsymbol{F}$ with higher magnification. $\boldsymbol{C}$, High-power micrograph of a symmetric presumed GABAergic synapse (arrowhead) emitted by the CCK-ir cell. The synapse innervates a dendritic shaft in the stratum moleculare. $\boldsymbol{D}$, Low-power $\left(\boldsymbol{D}_{\mathbf{1}}\right)$ and high-power of the framed area $\left(\boldsymbol{D}_{2}\right)$ micrographs of the leading dendrite innervated by an asymmetric synapse. $\boldsymbol{E}$, An asymmetric presumed glutamatergic synapse (arrowhead) innervating the trailing dendrite. $\boldsymbol{F}$, High-power micrograph of a symmetric synapse (arrowhead) innervating the $\mathrm{CCK}(+)$ cell body. G, A symmetric synapse (arrowhead) innervating the leading dendrite. Scale bars: $\boldsymbol{A}, 20 \mu \mathrm{m} ; \boldsymbol{B}, \boldsymbol{D}_{1}, 1 \mu \mathrm{m} ; \boldsymbol{C}_{\mathbf{2}} \mathbf{D _ { 2 }}-\mathbf{G}, 0.5 \mu \mathrm{m}$.

pared with the adjacent granule cells. They are unlikely to be false $\mathrm{CCK}(-)$ because penetration of immunoreagents in our material was complete and precipitation of the immunoperoxidase-DAB end product was very robust in every ultrathin section. Furthermore, elongated $\mathrm{CCK}(-)$ profiles are more numerous than $\mathrm{CCK}(+)$ profiles, indicating the presence of other types of migrating interneurons in the postnatal rat hippocampus (Fig. 6). Parvalbumin- and calretinin-containing cells that are situated at the border of the granular layer and the hilus are likely candidates.

Relationship between interneurons and GFAP $(+)$ glial cells To examine the mechanisms of migration of synaptically interconnected CCK $(+)$ cells, we performed confocal LM analysis of their contacts with neighboring glial cells. The contacts of $\mathrm{CCK}(+)$ and $\operatorname{GFAP}(+)$ cell bodies and processes were relatively rare and did not display consistent character (Fig. 7A-C). To take advantage of EM, we also performed labeling of GFAP with the immunoperoxidase-DAB method, whereas identification of migrating interneurons was based on the morphological criteria applied to $3 \mathrm{D}$ reconstructed cell bodies. Four reconstructed cell bodies situated in the granular and molecular layers had electron-dense cytoplasm and chromatin characteristic of hippocampal interneurons. Judging from the shape of the nuclei and proximal fragments of processes, these cells belong to our morphogenetic types A-D. Two of these cells had no direct contacts with $\operatorname{GFAP}(+)$ processes, although some processes were very close to them (Fig. 7D,E). The presence of $\operatorname{GFAP}(+)$ profiles in every analyzed ultrathin section make the possibility of falsenegative staining of these processes unlikely. The remaining two reconstructed interneurons had direct contact with glial processes (Fig. $7 F, G$ ), but these contacts were not completely tight. High-power EM analysis revealed, in some instances, an immunonegative membrane structure sandwiched between the glial processes and the interneuron cell bodies (Fig. $7 \mathrm{~J}, \mathrm{~K})$. In contrast, bipolar cells situated in the hilus (presumed to be immature granule neurons migrating toward the granular layer) demonstrated multiple, long, and tight contacts with $\operatorname{GFAP}(+)$ processes (Fig. $7 \mathrm{H}, \mathrm{I}$ ), as has been shown previously (Eckenhoff and Rakic, 1984). No $\operatorname{GFAP}(-)$ structures were sandwiched between migrating granule cells and $\operatorname{GFAP}(+)$ processes (Fig. $7 L, M$ ).

\section{Discussion}

In the present study, we performed LM and EM 3D reconstruction in combination with live imaging to monitor translocation of $\mathrm{CCK}(+)$ cells across the dentate plate. Virtually all the $\operatorname{CCK}(+)$ cells, which are initially detectable as horizontally oriented cells in the molecular layer, transform into tripolar and then to a vertical bipolar shape in the granular layer before settling at the interface with the hilus where they differentiate into typical pyramidal-shaped CCK $(+)$ interneurons. The observed morphogenetic cell transformation cannot be explained by differential programmed cell death, alteration in their immunoreactivity, or decrease in density as a result of growth of the neuropil in the molecular layer (Dupuy and Houser, 1997; Dupuy-Davies and Houser, 1999; Morozov and Freund, 2003). The major finding in the present study is not only that identified interneurons actually migrate, but also that they retain their synaptic connectivity during their migration. This is the first evidence that functionally active neurons can significantly change their position and represents a new example of brain plasticity.

The observed morphogenetic transformation of CCK $(+)$ cells 
is reminiscent of transformations of the cerebellar granule cells during their migration from the external granular layer across the developing molecular and Purkinje cell layers (Rakic, 1971; Komuro and Rakic, 1995). Initially, cerebellar granule cells move horizontally within the external granular layer (Komuro et al., 2001) and then transform into the tripolar cells, which extend the third vertical process to the molecular layers and translocate their nucleus and surrounding cytoplasm through that process to reach their final destination in the internal granular layer, where they first acquire synapses (Rakic, 1971). However, the CCK $(+)$ neurons have well defined input and output synapses while migrating.

The CCK $(+)$ cells, like most other interneurons of the rodent telencephalon, originate in the ganglionic eminence (see Introduction). However, whereas most interneurons terminate migration in the cortical plate, some invade the molecular layer of the hippocampal region (Pleasure et al., 2000; Polleux et al., 2002). We found that some of these cells begin to express CCK and become synaptically interconnected before starting a journey across the granular layer to settle at the interface with the hilus of the dentate gyrus. Thus, $\mathrm{CCK}(+)$ cells migrate in the opposite direction of the granule cells, which originate in the subgranular zone of the hilus and move radially along the glial processes to the granular layer (Eckenhoff and Rakic, 1984; Altman and Bayer, 1990).

Although migrating projection neurons and interneurons use different molecular cues and guidance substrates (Polleux et al., 2002; Ang et al., 2003; Stumm et al., 2003; Tanaka et al., 2003; Flames et al., 2004), both share some fundamental mechanisms (Rakic, 1990; Rakic et al., 1996; Hatten, 1999; Marin and Rubenstein, 2003). For example, subclasses of GABAergic interneurons in the human, which are generated in the neocortical proliferative zones, migrate along radial glial shafts, similar to the projection neurons (Letinic et al., 2002). However, the present results, obtained using double (CCK and GFAP) immunolabeling indicate that interneurons in the dentate gyrus have very sparse apposition to glial cells in contrast to the well defined contacts between radial glial processes and migrating granule cells. Thus, unlike radial migration of the projection neurons in the developing cerebral and cerebellar cortices (Rakic, 1971, 1972), interneurons moving across the rat dentate plate are not closely associated with radial glial shafts. Furthermore, because $\mathrm{CCK}(+)$ interneurons terminate their migration as soon as they reach the interface with the hilus, the interneurons situated in the deeper strata of the hilus may be generated locally. The finding of GABAergic cells in the hilus of the $D l \times 1 / 2$ mutant mice, which block interneuron migration from the ganglionic eminences, is consistent with this hypothesis (Pleasure et al., 2000).

A certain level of differentiation of migrating neurons has been observed previously in different systems. For example, pyramidal neurons in the developing primate hippocampus occa- sionally display initial signs of differentiation before reaching their final destination, as indicated by the presence of basally positioned axon-like processes (Nowakowski and Rakic, 1979). Likewise, prospective callosal neurons extend axons to the opposite hemisphere while migrating to the superficial layer of the neocortex (Schwartz et al., 1991). However, in the present study, most of the migrating cells demonstrated ultrastructurally well developed input and output synapses. The ability of interconnected neurons to move across dense cellular terrain without help from the radial glial guides opens the possibility that similar mechanisms may be used for migration of newly generated neurons in the adult dentate gyrus (for review, see Song et al., 2002). However, this may be even more widespread phenomenon used for recruitment of neurons from the healthy to the lesion area.

What controls the direction and rate of movement of the somas of CCK $(+)$ cells? In general, translocation of the nucleus and perinuclear cytoplasm during migration of immature neurons is associated with rearrangement of the cytoskeleton (Rivas and Hatten, 1995; Rakic et al., 1996). Furthermore, the rate of nuclear translocation depends of $\mathrm{Ca}^{2+}$ influx through $\mathrm{N}$-type $\mathrm{Ca}^{2+}$ channels and the NMDA subtype of the glutamate receptor (Komuro and Rakic, 1992, 1993) that affects depolarization of microtubules (Rakic et al., 1996), as shown in migrating cerebellar granule cells. The amplitude and frequency of $\mathrm{Ca}^{2+}$ intracellular fluctuations (Komuro and Rakic, 1996), in turn, depends on 

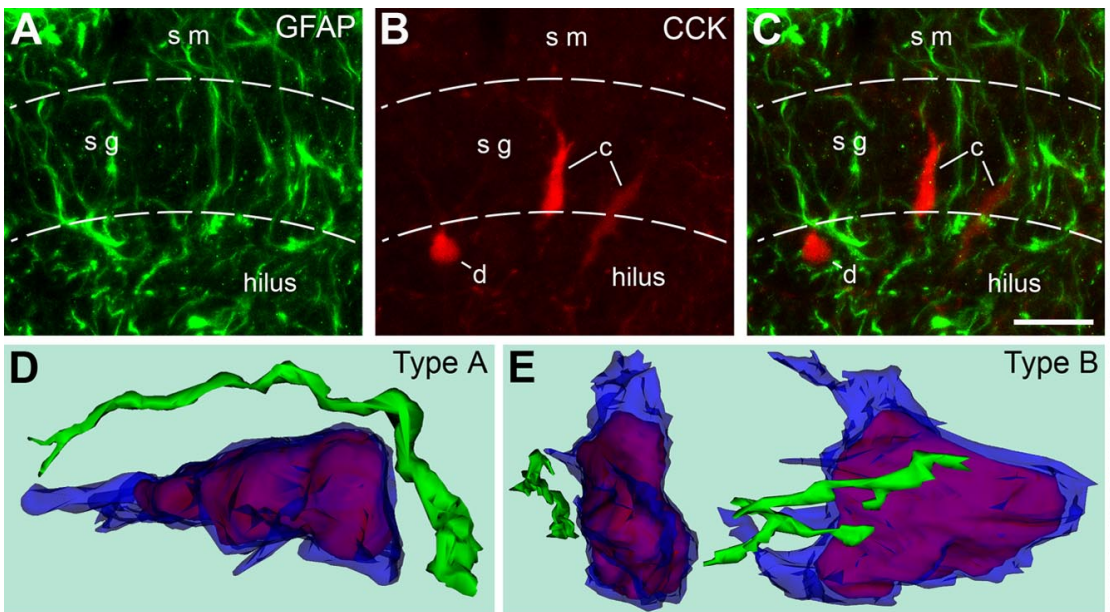

$\mathbf{F}$
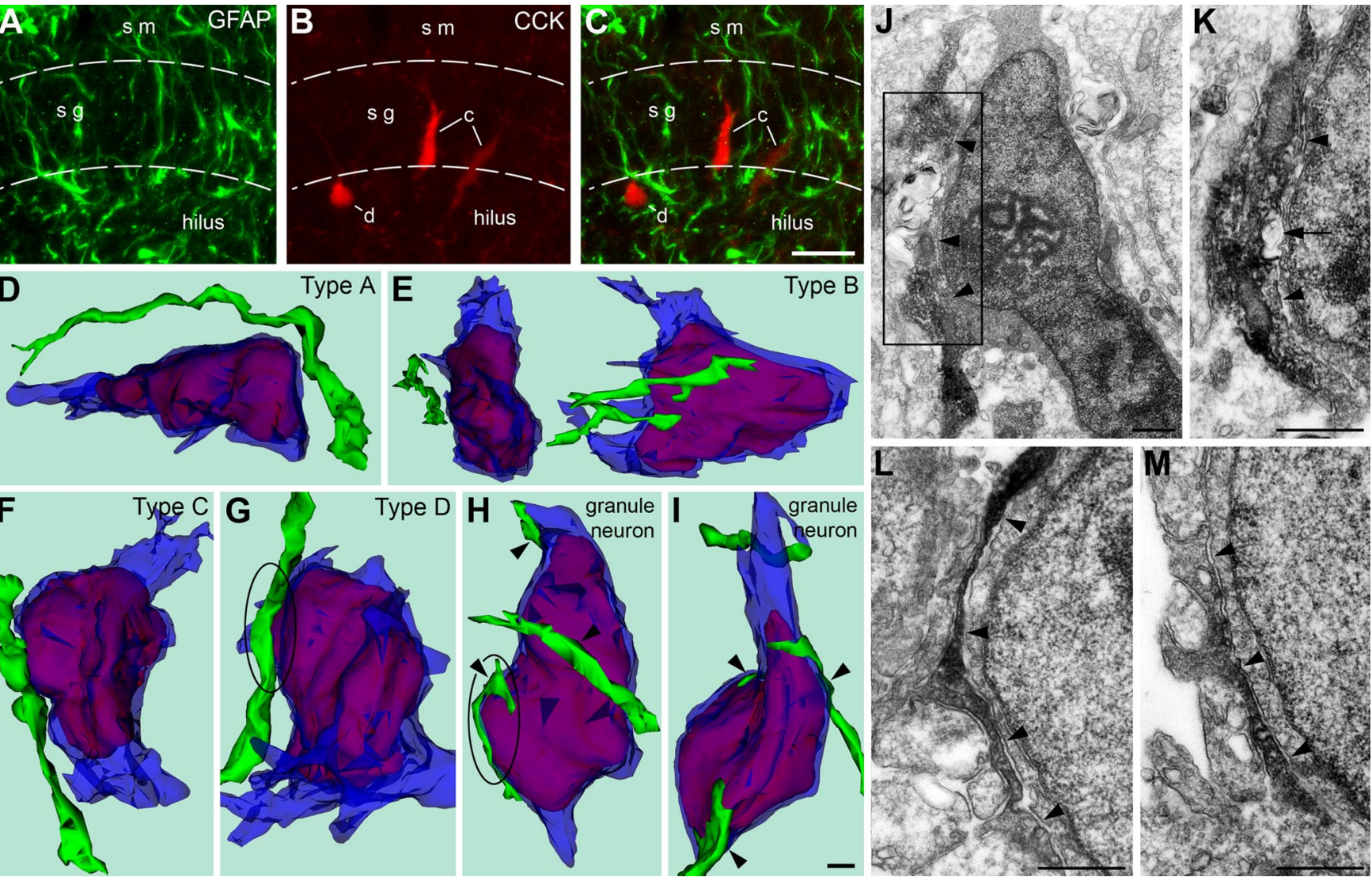

Figure 7. $\boldsymbol{A}-\boldsymbol{C}$, Confocal images of the hippocampal dentate gyrus of a 2-d-old rat after double immunolabeling of GFAP (green) and CCK (red). $\boldsymbol{A}$, Plenty of GFAP(+) processes are detectable in the strata moleculare (sm), granulosum (sg), and the hilus. B, Two bipolar vertical (type C; indicated with " $\mathrm{C}^{\prime \prime}$ ) and one pyramidal-shaped cell (type D; indicated with " $\mathrm{d}$ ") contain (CK in detectable quantities. C, CCK $(+)$ cells demonstrate several points of contact with GFAP $(+)$ glial processes. No distinct aligning of CCK $(+)$ and GFAP $(+)$ structures was found. D-I, Three-dimensional reconstructions of neuron cell bodies with proximal fragments of processes (semitransparent blue) and nuclei (red) in the dentate gyrus of a 4-d-old rat. GFAP( + ) processes (green) situated close to the reconstructed cell bodies were reconstructed as well. The bottoms of all the images are positioned to the direction of the hilus, and the tops to the stratum moleculare. Four of the reconstructed cells $(\boldsymbol{D}-\boldsymbol{G})$ demonstrated electron-dense cytoplasm and nucleoplasm, what is characteristic of hippocampal interneurons. Horizontal bipolar (D) and triangular (shown in two reciprocal perpendicular projections in $\boldsymbol{E}$ ) interneurons situated near the border of the strata moleculare and granulosum have no contacts with GFAP $(+)$ processes. GFAP $(+)$ processes have contacts with vertical bipolar $(\boldsymbol{F})$ and pyramidal-shaped $(\boldsymbol{G})$ interneurons situated in the granular layer but seem to follow an independent path. In contrast, bipolar cells situated in the hilus (presumed to be migrating granule neurons; $\boldsymbol{H}$ and $\boldsymbol{I}$ ) demonstrate tight contacts with several GFAP(+) processes (arrowheads). The zones framed with ovals in $\mathbf{G}$ and $\boldsymbol{H}$ are depicted in high-power EM micrographs in $\boldsymbol{J}-\boldsymbol{K}$ and $\boldsymbol{L}-\boldsymbol{M}$ respectively. $\boldsymbol{J}$, EM micrograph of the neuron shown in $\mathbf{G}$. This is an interneuron, what is suggested by pronounced electron-dense cytoplasm and nucleoplasm. GFAP(+) process (diffuse electron-dense DAB precipitation) demonstrates contacts with the plasma membrane of the interneuron in several fragments (arrowheads). Nevertheless, both upper and lower branches of the process disconnect and go away from the interneuron cell body. $\boldsymbol{K}$, High-power micrograph of a serial section from the area framed in $\boldsymbol{J}$. Notice an immunonegative membrane structure (arrow) sandwiched between the glial process and the interneuron cell body. $\boldsymbol{L}, \boldsymbol{M}$, High-power EM micrographs of serial, not adjacent sections ( $\sim 0.5 \mu \mathrm{m}$ in between) of the granule neuron depicted as a $3 D$ image in $\boldsymbol{H}$. Notice the immunoperoxidase-DAB-labeled GFAP-ir process leaning the cell body of the neuron for a long distance (arrowheads). Scale bars: (in C) $\boldsymbol{A}-\boldsymbol{C}, 20 \mu \mathrm{m}$; (in I) $\mathbf{D}-\mathbf{I}, 1 \mu \mathrm{m} ; \boldsymbol{J}-\mathbf{M}, 0.5 \mu \mathrm{m}$.

nonsynaptic neurotransmission activity that can be modified by the application of neurotransmitter modulators in a dosedependent manner, and it increases systematically with age (Komuro and Rakic, 1995; Behar et al., 1996). It may be significant that the density of input synapses innervating CCK $(+)$ interneurons in the dentate gyrus is upregulated during their early postnatal maturation (Morozov and Freund, 2003; present study).

We cannot exclude the possibility of constant synaptic turnovers on the migrating neurons as observed in some other experimental systems (Kirov et al., 1999; Pinto et al., 2004). However, there are several indications that some of the same synapses may persist while the cell is moving. Supplemental Figure 1 (available at www.jneurosci.org as supplemental material) provides a schematic illustration of the synaptic relationship during migration of GABAergic interneurons as observed in the present study. At the time a CCK $(+)$ interneuron (e.g., type B) extends the descending dendritic process to the granular layer, it already receives ultrastructurally defined synapses, probably from the entorhinal cor- tex and contralateral hippocampus (Super et al., 1998), while its axon forms synapses with granule cell dendrites. During migration across the granular layer, bipolar cells (type C) retain their input synapses in the molecular layer, but also acquire new contacts on the descending dendrite from granule cell axons. After arriving to the hilus, the soma of the interneuron (type D) receives numerous additional synapses from the collaterals of granule cell axons. Importantly, during the entire morphogenetic transformation, the interneuron retains the synaptic contacts with the dendrites of granule cells, as indicated by the development of the characteristic axonal loop. The model illustrated in supplemental Figure 1 (available at www.jneurosci.org as supplemental material) in which the nucleus and surrounding cytoplasm flows, whereas synaptically connected fragments of the cell membrane remain fixed (supplemental Fig. 1, synapses 2 and 3, available at www.jneurosci.org as supplemental material), is in harmony with the generally accepted mechanism of neuronal migration by nuclear translocation (Rakic, 1971, 1972; Sidman and Rakic, 1973; Rakic et al., 1996; Nadarajah et al., 2001), as well 
as with the observations that a new membrane is deposited at the growing tip of the leading process (Bray, 1973; Rakic, 1985). The membrane of the leading process may eventually passively transform into the somatic membrane as shown in the cerebellum (Komuro and Rakic, 1995).

We do not know what the functional significance of synapses on migrating neurons is. Interneurons in the adult hippocampus situated in the hilus send their dendrites to the molecular layer, whereas interneurons with the cell bodies in the molecular layer extend their dendrites to the hilus (for review, see Freund and Buzsaki, 1996). Thus, regardless of the cell body position, interneurons of the dentate gyrus receive synapses from the axons arriving to the hilus and molecular layer (supplemental Fig. 1, available at www.jneurosci.org as supplemental material). However, whether the position of synapses is on the somatic or dendritic surface has a profound physiological difference (Wong and Stewart, 1992; Miles et al., 1996). Thus, somas of interneurons translocate to the sites where they can receive more effective signals from the granule cells and, in this way, are converted into inhibitory basket interneurons back-regulating firing of the projection neurons. We propose that a requirement for a more effective synaptic communication may induce translocation of an already connected neuron to a more favorable position. Disturbance of this translocation, because of genetic and/or environmental factors, may cause a variety of deficits that rage from memory disorders to epilepsy.

\section{References}

Acsady L, Gorcs TJ, Freund TF (1996) Different populations of vasoactive intestinal polypeptide-immunoreactive interneurons are specialized to control pyramidal cells or interneurons in the hippocampus. Neuroscience 73:317-334.

Altman J, Bayer SA (1990) Migration and distribution of two populations of hippocampal granule cell precursors during the perinatal and postnatal periods. J Comp Neurol 301:365-381.

Altman J, Das GD (1965) Autoradiographic and histological evidence of postnatal hippocampal neurogenesis in rat. J Comp Neurol 124:319-336.

Anderson SA, Eisenstat DD, Shi L, Rubenstein JL (1997) Interneuron migration from basal forebrain to neocortex: dependence on Dlx genes. Science 278:474-476.

Ang Jr E, Haydar TF, Gluncic V, Rakic P (2003) Four-dimensional migratory coordinates of GABAergic interneurons in the developing mouse cortex. J Neurosci 23:5805-5815.

Ayoub AE, Cai TQ, Kaplan RA, Luo J (2005) Developmental expression of matrix metalloproteinases 2 and 9 and their potential role in the histogenesis of the cerebellar cortex. J Comp Neurol 481:403-415.

Bayer SA (1980) Development of the hippocampal region in the rat. I. Neurogenesis examined with $3 \mathrm{H}$-thymidine autoradiography. J Comp Neurol 190:87-114.

Behar TN, Li YX, Tran HT, Ma W, Dunlap V, Scott C, Barker JL (1996) GABA stimulates chemotaxis and chemokinesis of embryonic cortical neurons via calcium-dependent mechanisms. J Neurosci 16:1808-1818.

Ben-Ari Y, Khalilov I, Represa A, Gozlan H (2004) Interneurons set the tune of developing networks. Trends Neurosci 27:422-427.

Bray D (1973) Model for membrane movement in the neural growth cone. Nature 244:93-96.

Dupuy S, Houser C (1997) Developmental changes in GABA neurons of the rat dentate gyrus: an in situ hybridization and birthdating study. J Comp Neurol 389:402-418.

Dupuy-Davies S, Houser C (1999) Evidence for changing positions of GABA neurons in the developing rat dentate gyrus. Hippocampus 9:186-199.

Eckenhoff MF, Rakic P (1984) Radial organization of the hippocampal dentate gyrus: a Golgi, ultrastructural, and immunocytochemical analysis in the developing rhesus monkey. J Comp Neurol 223:1-21.

Fiala JC, Harris KM (2001) Extending unbiased stereology of brain ultrastructure to three-dimensional volumes. J Am Med Inform Assoc 8:1-16.

Flames N, Long JE, Garratt AN, Fischer TM, Gassmann M, Birchmeier C, Lai
C, Rubenstein JL, Marin O (2004) Short- and long-range attraction of cortical GABAergic interneurons by neuregulin-1. Neuron 44:251-261.

Freund TF, Buzsaki G (1996) Interneurons of the hippocampus. Hippocampus 6:345-470.

Gulyas AI, Miettinen R, Jacobowitz DM, Freund TF (1992) Calretinin is present in non-pyramidal cells of the rat hippocampus. I. A new type of neuron specifically associated with the mossy fibre system. Neuroscience 48:1-27.

Hatten ME (1999) Central nervous system neuronal migration. Annu Rev Neurosci 22:511-539.

Hevner RF, Daza RA, Englund C, Kohtz J, Fink A (2004) Postnatal shifts of interneuron position in the neocortex of normal and reeler mice: evidence for inward radial migration. Neuroscience 124:605-618.

Kirov SA, Sorra KE, Harris KM (1999) Slices have more synapses than perfusion-fixed hippocampus from both young and mature rats. J Neurosci 19:2876-2886.

Komuro H, RakicP (1992) Selective role of N-type calcium channels in neuronal migration. Science 257:806-809.

Komuro H, Rakic P (1993) Modulation of neuronal migration by NMDA receptors. Science 260:95-97.

Komuro H, Rakic P (1995) Dynamics of granule cell migration: a confocal microscopic study in acute cerebellar slice preparations. J Neurosci 15:1110-1120.

Komuro H, Rakic P (1996) Intracellular $\mathrm{Ca}^{2+}$ fluctuations modulate the rate of neuronal migration. Neuron 17:275-285.

Komuro H, Yacubova E, Yacubova E, Rakic P (2001) Mode and tempo of tangential cell migration in the cerebellar external granular layer. J Neurosci 21:527-540.

Kosaka T, Katsumaru H, Hama K, Wu JY, Heizmann CW (1987) GABAergic neurons containing the $\mathrm{Ca}^{2+}$-binding protein parvalbumin in the rat hippocampus and dentate gyrus. Brain Res 419:119-130.

Leranth C, Frotscher M (1986) Synaptic connections of cholecystokininimmunoreactive neurons and terminals in the rat fascia dentata: a combined light and electron microscopic study. J Comp Neurol 254:51-64.

Leranth C, Malcolm AJ, Frotscher M (1990) Afferent and efferent synaptic connections of somatostatin-immunoreactive neurons in the rat fascia dentata. J Comp Neurol 295:111-122.

Letinic K, Zoncu R, Rakic P (2002) Origin of GABAergic neurons in the human neocortex. Nature 417:645-649.

Lopez-Bendito G, Sturgess K, Erdelyi F, Szabo G, Molnar Z, Paulsen O (2004) Preferential origin and layer destination of GAD65-GFP cortical interneurons. Cereb Cortex 14:1122-1133.

Lubbers K, Wolff JR, Frotscher M (1985) Neurogenesis of GABAergic neurons in the rat dentate gyrus: a combined autoradiographic and immunocytochemical study. Neurosci Lett 62:317-322.

Marin O, Rubenstein JL (2003) Cell migration in the forebrain. Annu Rev Neurosci 26:441-483.

Miles R, Toth K, Gulyas AI, Hájos N, Freund TF (1996) Differences between somatic and dendritic inhibition in the hippocampus. Neuron 16:815-823.

Morozov YM, Freund TF (2003) Postnatal development and migration of cholecystokinin-immunoreactive interneurons in rat hippocampus. Neuroscience 120:923-939.

Nadarajah B, Brunstrom JE, Grutzendler J, Wong RO, Pearlman AL (2001) Two modes of radial migration in early development of the cerebral cortex. Nat Neurosci 4:143-150.

Nery S, Fishell G, Corbin JG (2002) The caudal ganglionic eminence is a source of distinct cortical and subcortical cell populations. Nat Neurosci 5:1279-1287.

Nowakowski RS, Rakic P (1979) The mode of migration of neurons to the hippocampus: a Golgi and electron microscopic analysis in fetal rhesus monkey. J Neurocytol 8:697-718.

Nunzi MG, Gorio A, Milan F, Freund TF, Somogyi P, Smith AD (1985) Cholecystokinin-immunoreactive cells form symmetrical synaptic contacts with pyramidal and nonpyramidal neurons in the hippocampus. J Comp Neurol 237:485-505.

Pinto S, Roseberry AG, Liu H, Diano S, Shanabrough M, Cai X, Friedman JM, Horvath TL (2004) Rapid rewiring of arcuate nucleus feeding circuits by leptin. Science 304:110-115.

Pleasure S, Anderson S, Hevner R, Bagri A, Marin O, Lowenstein D, Rubenstein J (2000) Cell migration from the ganglionic eminences is required 
for the development of hippocampal GABAergic interneurons. Neuron 28:727-740.

Polleux F, Whitford KL, Dijkhuizen PA, Vitalis T, Ghosh A (2002) Control of cortical interneuron migration by neurotrophins and PI3-kinase signaling. Development 129:3147-3160.

Rakic P (1971) Neuron-glia relationship during granule cell migration in developing cerebellar cortex. A Golgi and electronmicroscopic study in Macacus Rhesus. J Comp Neurol 141:283-312.

Rakic P (1972) Mode of cell migration to the superficial layers of fetal monkey neocortex. J Comp Neurol 145:61-83.

Rakic P (1985) Contact regulation of neuronal migration. In: The cell in contact: adhesions and junctions as morphogenetic determinants (Edelman GM, Thiery JP, eds), pp 67-91. New York: Wiley.

Rakic P (1990) Principles of neural cell migration. Experientia 46:882-891.

Rakic P, Knyihar-Csillik E, Csillik B (1996) Polarity of microtubule assemblies during neuronal cell migration. Proc Natl Acad Sci USA 93:9218-9222.

Rivas RJ, Hatten ME (1995) Motility and cytoskeletal organization of migrating cerebellar granule neurons. J Neurosci 15:981-989.

Rowley III JC, Moran DT (1975) A simple procedure for mounting wrinklefree sections on formvar-coated slot grids. Ultramicroscopy 1:151-155.

Schwartz ML, Rakic P, Goldman-Rakic PS (1991) Early phenotype expression of cortical neurons: evidence that a subclass of migrating neurons have callosal axons. Proc Natl Acad Sci USA 88:1354-1358.

Sidman RL, Rakic P (1973) Neuronal migration with special reference to developing human brain: a review. Brain Res 62:1-35.
Song HJ, Stevens CF, Gage FH (2002) Neural stem cells from adult hippocampus develop essential properties of functional CNS neurons. Nat Neurosci 5:438-445.

Soriano E, Cobas A, Fairen A (1986) Asynchronism in the neurogenesis of GABAergic and non-GABAergic neurons in the mouse hippocampus. Brain Res 395:88-92.

Stumm RK, Zhou C, Ara T, Lazarini F, Dubois-Dalcq M, Nagasawa T, Hollt V, Schulz S (2003) CXCR4 regulates interneuron migration in the developing neocortex. J Neurosci 23:5123-5130.

Super H, Martinez A, Del Rio JA, Soriano E (1998) Involvement of distinct pioneer neurons in the formation of layer-specific connections in the hippocampus. J Neurosci 15:4616-4626.

Tanaka D, Nakaya Y, Yanagawa Y, Obata K, Murakami F (2003) Multimodal tangential migration of neocortical GABAergic neurons independent of GPI-anchored proteins. Development 130:5803-5813.

Yozu M, Tabata H, Nakajima K (2005) The caudal migratory stream: a novel migratory stream of interneurons derived from the caudal ganglionic eminence in the developing mouse forebrain. J Neurosci $25: 7268-7277$

Wichterle H, Garcia-Verdugo JM, Herrera DG, Alvarez-Buylla A (1999) Young neurons from medial ganglionic eminence disperse in adult and embryonic brain. Nat Neurosci 2:461-466.

Wong RK, Stewart M (1992) Different firing patterns generated in dendrites and somata of CAl pyramidal neurons in guinea-pig hippocampus. J Physiol (Lond) 457:675-687. 